\title{
Vaccination Strategies in NSCLC Patients
}

\section{Benedikt Gahn*}

$2^{\text {nd }}$ Department of Medicine, University Medical Center Schleswig-Holstein, Chemnitzstraße 33, 24116 Kiel, Germany

\begin{abstract}
Non Small Cell Lung Cancer (NSCLC) is often diagnosed in an advanced stage. In this setting the disease is associated with an unfavourable prognosis. Although recent therapeutic advances using molecularly targeted agents enable an improved prognosis, most patients still have a poor outcome. Many tumor antigens have been identified in NSCLC and the activation of tumour antigen-specific immunity mediated by vaccination strategies is widely accepted as an attractive new therapeutic strategy.

Different therapeutic cancer vaccines are currently under clinical development. In clinical studies vaccination protocols targeting tumour antigens like MAGE-A3, MUC1 and hTERT have resulted in favourable survival data. Mode of action as well as available clinical data in phase II and III studies are reviewed. The success of this ongoing tumour antigen-specific vaccination approaches is hampered by local immunosuppressive factors like TGF- $\beta$ and PD-1. Promising data have been obtained by inhibition of these factors facilitating effective tumour specific immune responses. Also in this particular field we will give an update on the most promising approaches.
\end{abstract}

\section{Introduction}

Patients with advanced non-small cell lung cancer (NSCLC) still have an unfavourable prognosis. Even though advances have been made both in diagnostic and therapeutic modalities, limited improvement in prognostic outcome of patients with advanced NSCLC has been accomplished. Particularly in patients with epidermal growth factor receptor (EGFR) mutations tyrosine kinase inhibitors enable an improved prognosis. However, patients not showing a molecular mutation treatable by specific tyrosine kinase inhibitors still have an unsatisfactory median survival of 8 months only [1].

These poor survival data in patients with advanced NSCLC demonstrate the urgent need for alternative therapies. Recent advantages in tumour immunology have pointed to the influence of tumour-specific, cellular immune responses on the proliferation of malignant cells and tumour development [2]. Potentially immunologically distinct antigens that are expressed by tumour cells can be targeted by the patient's immune system [3]. As a matter of fact, cellular immune responses have been discussed as mechanisms of tumour growth suppression [4]. It is well accepted that artificial immunity can efficiently control and even eradicate established tumours [5]. Harnessing the anti-tumour potential of T-cells, in particular $\mathrm{CD}^{+}$cytotoxic T-lymphocytes (CTL), is a promising strategy for cancer cell eradication. Due to their relative ease of administration and documented low toxicities vaccines that trigger $\mathrm{T}$-cell responses are very attractive therapeutic approaches.

In NSCLC patients the expression of HLA class I molecules is associated with a favourable prognosis and less lymph node metastases $[6,7]$. Cytotoxic T lymphocytes migrate into the tumour epithelium [8] potentially recognizing tumour antigens presented by HLA class I molecules. Moreover, careful clinicopathological studies show that high numbers of tumour- and stroma-infiltrating CTLs are associated with an increased disease-specific survival [9]. These findings point to a CTL-mediated antitumour response supporting immunotherapeutic approaches in NSCLC patients.

CTL can detect and destroy [2,3] tumour cells by recognition of Tumour-Associated Antigens (TAA). These TAA are peptides bound to major histocompatibility molecules that are expressed on the surface of tumour cells. Similar to viral antigens like CMVor EBV-antigens, TAA are degraded by the proteasome into short peptides, transported to the endoplasmic reticulum, packaged in the MHC molecules and delivered as peptide-MHC complexes to the cell surface. These peptide-MHC complexes are recognized by specific $\mathrm{T}$ cell receptors (TCR) leading to the activation of TCR bearing CTLs. The activated CTLs proliferate, produce cytokines and lyse target cells presenting the same MHC bound TAA. Advances in tumour immunology have demonstrated that TAA activate cancer-specific $\mathrm{T}$ cell responses. In straight forward studies the target structures of cancer-specific $\mathrm{T}$ cells have been identified by molecular analysis of patient derived $\mathrm{T}$ cells $[10,11]$. These studies have been done initially in melanoma patients and tumour samples, but have been extended quickly to other malignancies. The results support concepts of tumour imunosurvaillance by T-lymphocytes that can specifically attack and destroy TAA expressing tumour cells [10,11-13]. In animal models as well as in subsequent clinical trials it has been shown that tumour antigen-specific T lymphocytes can cause tumour regression [14] and multiple TAA have been identified so far [15].

TAA suitable for immuno therapeutical approaches should be stably and specifically expressed by malignant but not by healthy cells. These tumour-associated antigens are subdivided in Cancer/ Testis (CT) antigens, differentiation antigens, over expressed antigens, mutated antigens and viral antigens. In non-small cell lung cancer all of these tumour-associated antigens have been described [16-21].

\section{MAGE-A3 Directed Vaccination}

Cancer-testis (CT) antigens are specifically expressed by malignant cells. However, in normal tissues also the testes express CT antigens.

*Corresponding author: Benedikt Gahn MD, Assistant Professor, $2^{\text {nd }}$ Department of Medicine, University Medical Center Schleswig-Holstein Chemnitzstr 33, 24116 Kiel, Germany, Tel: 04311697 5213; Fax: 0431 1697-1213; Email: B.Gahn@med2.uni-kiel.de

Received September 30, 2013; Accepted November 06, 2013; Published November 11, 2013

Citation: Gahn B (2013) Vaccination Strategies in NSCLC Patients. J Mol Genet Med 7: 88. doi: 10.4172/1747-0862.1000088

Copyright: (c) 2013 Gahn B. This is an open-access article distributed under the terms of the Creative Commons Attribution License, which permits unrestricted use, distribution, and reproduction in any medium, provided the original author and source are credited 
Because the testes do not have HLA class I molecules, activation of CT-specific immune responses should not cause autoimmunity. In malignant melanoma the melanoma-associated antigen gene (MAGE)-A3 has been identified as a tumour associated antigen [22]. Nevertheless, this CT antigen is expressed not only in melanoma but also in gastrointestinal cancers and non-small cell lung cancer. Furthermore, within the MAGE-A3 protein there are a number of peptides that can be presented by HLA class I and class II molecules and can be targeted by $\mathrm{CD} 4^{+}$and $\mathrm{CD} 8^{+} \mathrm{T}$ lymphocytes.

The MAGE-A3 CT antigen is expressed in NSCLC of about 35\% of patients with local and locally advanced disease. The treatment of choice is the surgical resection with curative intent. In a randomized, placebo controlled phase II study patients with MAGE-A3-positive stage IB to II NSCLC underwent standard treatment with complete tumour resection. As an adjuvant therapy patients received vaccinations with a recombinant MAGE-A3 protein in combination with an immunostimulant. In this study clinical outcome, immune responses as well as safety issues after MAGE-A3 immunization were analyzed. In a survival analysis performed 44 months after surgery $35 \%$ of vaccinated patients relapsed. In the control group $43 \%$ of patients relapsed. Although this was a trend to better survival after vaccination, data in disease-free survival and overall survival were not significantly different [23]. In a large phase III study these results will be analyzed in more detail.

\section{hTERT Directed Vaccination Studies}

The human telomerase reverse transcriptase (hTERT), the catalytic subunit of telomerase, is a TAA being overexpressed in almost all malignant tumours and absent or expressed at low level in normal human tissue [24-27].

Within the human telomerase reverse transcriptase (hTERT) multiple epitopes have been identified leading to the investigation of this tumour antigen as a broadly applicable immunological target. Basic immunological studies have demonstrated that peptides derived from hTERT are naturally processed by tumours, presented on MHC molecules and trigger effector functions of specific CTL.

Clinical trials of multiple vaccine formulations have illustrated that hTERT-specific immune responses can be safely induced in cancer patients and have a noticeable impact on clinical results. However, using the short peptide hTERT 540-548 for vaccination in immuntherapy studies differing results of efficacy have been reported [28-31]. In contrast, vaccinations with long peptides or hTERT mRNA have shown more promising results [32-38].

hTERT is expressed in $93-100 \%$ of NSCLC $[39,40]$ rendering hTERT an attractive target for antigen-specific immunotherapy in NSCLC patients. In vitro hTERT-specific T cells could be activated in patients with advanced NSCLC [41]. Clinical studies using the GV1001 polypeptide for vaccination have been initiated. GV1001 is a polypeptide consisting of the hTERT amino acids 611-626. This 16-mer promiscuous polypeptide contains fragments with binding affinity to multiple HLA-class II molecules. Since these HLA-class II molecules include HLA-DR,-DP and -DQ loci, T helper (Th) responses are activated in up to $80 \%$ of vaccinated patients [37]. GV1001 also contains peptides with binding affinity to HLA-class I molecules, potentially leading to the activation of both $\mathrm{CD} 4^{+}$and $\mathrm{CD} 8^{+} \mathrm{T}$-cell responses that are thought to be important for eliciting memory $\mathrm{T}$ cell responses and systemic tumour cell destruction.

In patients with advanced non-small cell lung cancer two clinical trials of vaccination with the telomerase peptide GV1001 have been performed. In these studies the activation of specific immune responses, the toxicity and the clinical efficacy have been evaluated: A phase I/ II trial (CTN-2000) in which 8-year follow up data are now available [33] as well as a phase II trial (CTN-2006) in which patients had been vaccinated after chemoradiotherapy [42] have been published recently.

In the CTN-2000 trial two different hTERT peptides, GV1001 and I540, have been used for vaccination in NSCLC patients. In 13/24 evaluable patients a GV1001-specific immune response could be idenified by T-cell proliferation and cytokine assays. The immune responders had a significant better median survival than nonresponders (19 months vs 3.5 months). Detailed immunologic analysis of four long-time survivors demonstrated long lasting GV1001-specific T-cell memory responses in all four patients. In a follow up of more than 9 years two of these patients achieved a complete remission. After 108 and 93 months, respectively, both patients are without any signs of relapse. These two patients are still receiving booster injections and keep stable GV1001-specific immune reactions.

In the CTN-2006 trial 23 patients with non resectable stage III NSCLC were included. The study treatment consisted of radiotherapy $\left(30 \times 2\right.$ Gy) in combination with weekly docetaxel $\left(20 \mathrm{mg} / \mathrm{m}^{2}\right)$. This concomitant radiochemotherapy was followed by GV1001 vaccination. In 16 out of 20 patients who had been immunologically analyzed a GV1001-specific immune response was detected. In 13 patients long persistance of these GV1001-specific immune responses was shown. There were no reports of serious adverse events. Patients with GV1001specific immune response had a median progression free survival (PFS) of 371 days, whereas nonresponders had a median PFS of 182 days only. These results show a trend associating a positive immune response with extended PFS.

Both the CTN-2000 and the CTN-2006 showed the safety of GV1001 vaccinations. Furthermore in most NSCLC patients the vaccination established durable GV1001-specific T-cell reactivity. The reported data show that vaccination with hTERT peptides activates specific $\mathrm{T}$-cell responses with $\mathrm{CD}^{+}$and $\mathrm{CD}^{+} \mathrm{T}$-cell compartments both that are needed for tumour eradication. These broad hTERT reactivities mediated advantages both in overall survival (CTN 2000) and progression free survival (CTN 2006). The observed survival advantages in immune responders support the combination of chemoradiotherapy with vaccination and warrant further randomized trials.

Tumour-specific vaccination approaches predominantely aim at the activation of cytotoxic $\mathrm{T}$ cells that are recognizing endogenously processed dominant peptides derived from TAAs and presented on the tumour cell surface on HLA class I molecules. Dominant peptides bind with high affinity to HLA class I molecules but due to tolerance this approach is of limited efficiacy in cancer immunotherapy as activated T cells potentially get deleted $[43,44]$.

A promising approach of breaking tolerance to tumour antigens is the activation of $\mathrm{T}$ cells specific for cryptic peptides. Advanced immunological studies have shown that $\mathrm{T}$ cells specific for cryptic peptides are not deleted and escape tolerance [43,45-47]. However, cryptic peptides have low affinity to HLA I molecules leading to low immunogenicity. To improve their HLA I binding capacity cryptic pepides can be optimized by modification of their amino acid sequence. Rendering it immunogenic the cryptic hTERT ${ }_{572}$ peptide was modified resulting in the optimized, cryptic, HLA-A*0201-binding, hTERT $_{572 \mathrm{Y}}$ peptide (Vx-001; Vaxon Biotech, Evry, France). In vitro, 


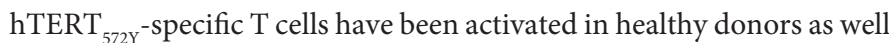
as in prostate cancer patients. These $\mathrm{T}$ cells recognized and destroyed hTERT-expressing tumour cells. However, normal cells expressing hTERT were not killed [48]. In HLA-A ${ }^{*} 0201$ transgenic mice [49] hTERT $_{572 Y}$ activated a tumour-specific immune response without any signs of autoimmunity $[45,48]$.

In NSCLC in a study enrolling HLA-A2 ${ }^{+}$patients the clinical efficiacy of vaccination with optimized low-affinity hTERT peptides was investigated. This study had been started at the University General Hospital of Heraklion, Crete. In this clinical trial 22 patients with advanced NSCLC and residual $(n=8)$ or progressive disease $(n=14)$ have been vaccinated with $\mathrm{V} \times-001$ consisting of the optimized peptide telomerase reverse transcriptase TERT $_{572 Y}$ presented by HLA-A ${ }^{\star} 0201$. After chemotherapy and/or radiotherapy the TERT $T_{572 y}$ peptide combined with a Montanide adjuvant was administered subcutaneously. In this study the immune response, the clinical response as well as the safety of the $\mathrm{Vx}-001$ vaccination was investigated [50]

Following two injections of the optimized TERT $_{572 Y}$ peptide four injections of the native TERT $_{572}$ peptide were given. The activation of TERT $_{572}$-specific $\mathrm{T}$ cell responses was analyzed by enzyme-linked immunosorbent spot assay. In addition $\mathrm{T}$ cells were stained with a TERT $_{572 Y}$ pentamer and analyzed by flow cytometry. Peptide-specific $\mathrm{T}$ cell responses were observed in the majority of patients without toxicity. After two vaccinations activation of TERT ${ }_{572}$-specific $\mathrm{T}$ cells was detected in $16(76 \%)$ of 21 patients. After six vaccinations the number of responding patients mounting a TERT-specific immune response increased to 10 (91\%) of 11 patients. In the clinical follow up Stable Disease (SD) was observed in eight (36\%) out of 22 vaccinated patients. The median duration of SD was 11 months. After a median follow-up of 10 months, patients with early activated TERT-specific $\mathrm{T}$ cell responses had a significantly longer time to progression and Overall Survival (OS) than patients not activating TERT-specific T cell responses. The estimated median OS in responders was 30 months whereas in non responders the OS was 4.1 months only.

In this study it was shown that the TERT $\mathrm{T}_{572 \mathrm{Y}}$ peptide vaccine is well tolerated and is activating TERT-specific T cell responses. Patients activating TAA-specific $T$ cells after two vaccinations have a significant better survival. However, further randomized, phase III studies are needed to confirm these results.

\section{Vaccination Approaches Targeting MUC1}

Mucin 1 (MUC1) is a transmembrane, highly glycosylated protein that is expressed at the apical surface of normal epithelial cells. In its extracellular part the MUC1 glycoprotein contains the "variable number of tandem repeats (VNTR)". A single tandem repeat consists of the 20-amino-acid sequence PDTRPAPGSTAPPAHGVTSA. The number of VNTR is varying from 25 to 120 VNTR per MUC1 molecule [51].

In malignant cells this glycoprotein is often highly expressed with a modification of its glycosylation pattern [52]. There are a number of antigens exposed in cancer that are masked in normal mammary tissue by glycosylation. Both the overexpression of the MUC1 protein and the modification of its glycosylation pattern turn this glycoprotein into a highly immunogenic protein facilitating cancer-specific immunotherapy studies. A cancer vaccine targeting MUC1 antigens will only eliminate cancer cells, normal cells should stay untouched. The differences observed between MUC1 as it is expressed by tumour cells and MUC1 as it is expressed by healthy cells prompted research on the investigation if $\mathrm{T}$ cells specifically recognize MUC1 tumour epitopes.

Usually $\mathrm{T}$ cells recognize their target antigen by binding of the T-cell receptor to the complex structure of epitope peptide and MHC molecule. However, initial analyses demonstrated MHC-unrestricted recognition of tumour-associated MUC1 by human cytotoxic T lymphocytes [53]. The $\mathrm{T}$ cells from a pancreatic cancer patient did not bind to the MUC1 peptide presented by the MHC molecule, but bound directly to the hypoglycosylated MUC1 peptide. The use of MHC restricted TAA is limited to a subgroup of patients with a particular HLA. T cells that bind directly to MUC1 peptides would enable MUC1specific $\mathrm{T}$ cell therapy in all patients independent of their HLA-type.

Further studies were initiated to identify HLA-restricted, MUC1specific T-cell responses. In the VNTR Domenech and colleagues identified the STAPPAHGV peptide. This MUC1-peptide binds to the HLA class I molecules HLA-A1, -A2.1, -A3, and -A11 [54]. In this study CD8 ${ }^{+}$CTLs specific for the HLA-A11/STAPPAHGV complex were activated. However, it was not analyzed if these $\mathrm{T}$ cells did also recognize the peptide on HLA-A $11^{+}$tumour cells. In HLA-A ${ }^{\star} 0201 /$ $\mathrm{Kb}$ transgenic mice two MUC1 peptides binding to HLA- ${ }^{\star} 0201$, STAPPAHGV, confirming previous data, and the APDTRPA peptide, have been identified in the VNTR [55].

Two other MUC1 peptides with good affinity to HLA-A ${ }^{\star} 0201$, LLLLTVLTV and STAPPVHNV, have been described by Brossart et al. [56]. The LLLLTVLTV peptide is encoded by the signal sequence of MUC1, whereas the STAPPVHNV is part of the flanking region of the VNTR.

In addition, one HLA-DR3-restricted MUC1 epitope, that is encoded by the VNTR and can be recognized by CD4+ T lymphocytes, has been identified [57].

These data obtained in preclinical studies are now investigated in clinical phase IIB/III trials with MUC1-specific immunotherapy in NSCLC patients. L-BLP25 (Stimuvax ${ }^{\oplus}$ ) is a liposomalvaccine designed to induce immune responses to MUC1 expressing cancer cells. It contains the 25-amino-acid peptide STAPPAHGVTSAPDTRPAPGSTAPP corresponding to the core peptide of MUC1. At the $\mathrm{C}$ terminus this polypeptide is coupled with a palmitoyl lysine residue facilitating incorporation of this lipopeptide into the liposome [58,59]. Structural lipids promote antigen uptake by antigen-presenting cells and, hence, immune responses. Furthermore the lipid adjuvant potentiates T-cell response by inducing proinflammatory cytokines.

The L-BLP25 liposomal vaccine has been given to patients with NSCLC and was tolerated well $[60,61]$. In a phase II study in patients with stage IIIB/IV NSCLC vaccination with L-BLP25 was associated with an impressive, although not significant survival benefit. However, specific immunological responses were not seen [62]. Based on these promising results a randomized phase III study (START) with L-BLP25 vaccination was performed in patients with advanced NSCLC. Standard therapy of unresectable stage III A/B NSCLC consists of platinum-based chemotherapy with concurrent thoracic radiation leading to a 5-year survival of $15 \%$ only. In the START study 1513 pts with stage III NSCLC that could not be surgically resected and that did not progress after radiochemotherapy were randomized to L-BLP25 or placebo (PBO). Cyclophosphamide $300 \mathrm{mg} / \mathrm{m}^{2}$ or saline was given 3 days prior to first L-BLP25/PBO dose. While the median survival in patients receiving sequential chemoradiotherapy was not significantly improved subgroup analysis of patients with concurrent chemoradiotherapy $(n=806)$ showed a median OS of $30.8 \mathrm{~m}$ (L-BLP25) 
vs. $20.6 \mathrm{~m}$ (PBO). Specifically, the trial showed a striking $10.2 \mathrm{month}$ difference in favour of L-BLP25 vaccinated patients $(\mathrm{p}=0.016)$.

In conclusion L-BLP25 maintenance therapy in stage III NSCLC did significantly prolong OS in patients receiving concurrent radiochemotherapy.

An interesting approach is the use of a recombinant virus, TG4010, a modified Vaccinia Ankara virus. This recombinant virus is encoding both MUC1 and the immunostimulatory cytokine IL-2. Clinical and immunological activity of TG4010 has been investigated in prostate cancer, renal cell carcinoma (RCC), and NSCLC [63-65]. In prostate cancer patients the doubling time of prostate-specific antigen (PSA) was improved, indicating therapeutic activity of TG4010 [64]. In RCC MUC1-specific T cell responses were observed after TG4010 vaccination [65]. In lung cancer patients vaccination with TG4010 prolonged progression free survival by six months. In this study patients received either chemotherapy in combination with the TG4010 vaccine or chemotherapy only [66]. To analyze the combination of chemotherapy and TG4010 in NSCLC patients these data are currently investigated in a phase IIB/III study.

\section{Perspectives}

Considering the therapeutic success of vaccination therapy especially in NSCLC patients the activation of tumour-specific T cell responses warrants further work to address the identification of biomarkers for patients eligible for therapeutic vaccination.

In a recent study the gene expression signature of vaccinated NSCLC patients was analyzed to identify biomarkers for the activation of MAGE-A3 antigen-specific T cell responses [67]. For detection of the pretreatment gene expression signature (GS) predicting the clinical course after MAGE-A3 vaccination tumour samples of early stage NSCLC patients were analyzed. mRNA from tumour biopsies of MAGE-A3 vaccinated patients was analyzed by microarray analysis and quantitative polymerase chain reaction. In a phase II trial patients had been vaccinated with the MAGE-A3 TAA and the immunostimulant AS02B [23]. The expression of 84 genes that had previously been identified in melanoma patients was associated with clinical benefit. After vaccination GS-positive patients had better disease-free survival than placebo-treated GS-positive patients, whereas GS-negative patients did not show any difference. However, the differences were not statistically significant. The gene signature associated with a favourite prognosis was characterized by components of antigen processing as well as overexpression of MHC class I and II molecules. In addition $\mathrm{T}$ cell markers and genes coding for chemokines that support $\mathrm{T}$ cell infiltration of the tumour microenvironment were over expressed. These results suggest that the clinical response depends on the expression of the gene signature in the tumour microenvironment. In patients with early stage NSCLC, that had been treated with tumour resection and MAGE-A3 vaccination the 84-gene GS was related to a favourite clinical course.

Although human cancers harbor antigens that can be targeted by TAA-specific T lymphocytes the immune system is repeatedly unable to mediate functional $\mathrm{T}$ cell responses. A number of patients with activated tumour-specific $T$ cell response do not benefit from these TAA-specific lymphocytic cell populations. Tumours have or may develop multiple mechanisms of resistance.

Programmed death 1 (PD-1) is normally expressed by activated T cells. PD-1 ligands like PD-L1 and PD-L2 can be expressed by tumour and stromal cells mediating $\mathrm{T}$ cell apoptosis and immuno supression
[68]. In preclinical studies the blockade of PD-1 and PD-L1 binding increased $\mathrm{T}$-cell activation resulting in tumour-specific $\mathrm{T}$ cell activity in vitro [69].

In a clinical trial 296 cancer including lung cancer patients were treated with the monoclonal antibody BMS-936558, a specific antiPD-1 antibody [70]. In patients with NSCLC clinical responses were reported in 33\% of patients with squamous cell lung cancer and $12 \%$ with nonsquamous cell cancer. In 8 patients clinical response lasted at least 6 months, 2 patients had a 1 year ongoing response.

Potentially in patients with cancer cells expressing PD-L1 the inhibition of binding to PD-1 expressed on T cells may unleash an endogenous antitumour immune response. It remains unknown why only a subgroup of patients was responding to the anti-PD-1 antibody. However, in the above mentioned study 42 cancer patients were analyzed for the expression of PD-1L. There was a significantly higher clinical response rate in patients with $\mathrm{PD}-1 \mathrm{~L}$ positive tumour samples whereas in patients with PD-1L negative tumours there was no clinical response.

Transforming growth factor beta (TGF- $\beta$ ) is an immunosuppressive cytokine regulating both growth and function of healthy as well as cancer cells [71]. An increased production of TGF- $\beta 2$ is associated with immunosuppression in cancer patients $[72,73]$ and in patients with NSCLC high levels of TGF- $\beta 2$ are correlated with an unfavourable prognosis [74]. Using an antisense gene inhibiting TGF- $\beta 2$, cellular TGF- $\beta 2$ production was decreased. This blockade of TGF- $\beta 2$ expression resulted in increased immunogenicity of gene-modified cancer cells [75].

Based on these results a randomized phase II study of vaccination with belagenpumatucel-L was conducted in NSCLC patients [76] Belagenpumatucel- $\mathrm{L}$ is an allogeneic tumour cell vaccine consisting of four NSCLC lines that had been transfected with the TGF- $\beta 2$ antisense transgene. Focusing on patients with advanced disease $15 \%$ of patients got a partial response. In 61 patients with advanced stage IIB and IV NSCLC the immune responses were analyzed. An increase in IFN- $\gamma$ producing cells was observed among clinical responders. In these patients also a response mediated by antibodies to the vaccine's HLAs was detected. In addition, $T$ cell reactivity to belagenpumatucel- $\mathrm{L}$ shown by ELISPOT analysis was linked to a trend to clinical response.

\section{Conclusion}

Comparing the above mentioned studies clinical success in NSCLC patients was observed in all vaccination protocols. However, MAGE-A3 vaccination in patients with resected, local disease was associated with a trend to better survival only. Interestingly the gene signature identified in this study was correlated with an improved prognosis. However, these data again were not significant and showed a trend only to better survival in favour of patients with the GS

In contrast in patients with locally advanced, non resectable stage III NSCLC GV1001 vaccination demonstrated a significant better survival in immune responders. The detailed analysis of $\mathrm{T}$ cell responses before and after vaccination was a major advantage of the CTN 2000 and the CTN 2006 study. These analyses demonstrated the activation of both $\mathrm{CD}^{+}$and $\mathrm{CD} 8^{+} \mathrm{T}$ cells making attractive the use of polypeptides in vaccination protocols. The induction of long lasting $\mathrm{T}$ cell responses associated with ongoing clinical remissions further supports this approach.

Similarly in patients with advanced disease who had been 
vaccinated with the hTERT ${ }_{572 Y}$ peptide $(\mathrm{Vx}-001)$ and activated a TAAspecific $\mathrm{T}$ cell response a significant survival benefit was observed. The activation of hTERT- specifc T cell responses in $91 \%$ of vaccinated patients strongly supports the use of cryptic peptides in vaccination protocols.

Also the START study showed a significant survival benefit in patients with locally advanced disease. The survival advantage was limited to patients who received L-BLP25 vaccination after concomitant radio chemotherapy. Unfortunately the START-study did not analyze the TAA-specific T cell response in detail. However, the L-BLP25 again is a polypeptide containing a number of HLA class I restricted peptides. Potentially also HLA class II peptides are located within the L-BLP25 facilitating $\mathrm{CD}^{+}$in combination with $\mathrm{CD} 8^{+} \mathrm{T}$ cell responses.

To identify those patients capable of activating a TAA-specific immune response biomarkers would be desirable. Since specific markers are still missing biomarkers predicting the activation of TAAspecific immune responses are urgently needed. Further investigation of $\mathrm{T}$ cell gene signature might detect even more genetic factors crucial for efficient immune responses. In addition the detailed analysis of immune inhibitory molecules in the tumour microenvironment could enable protocols with blockade of immune suppressive factors like $\mathrm{PD}-1 \mathrm{~L}$ and TGF $\beta$. If efficient $\mathrm{T}$ cell activation in vaccination protocols with polypeptides and optimized, cryptic peptides is combined with blocking of immune inhibitory pathways clinical benefit in all NSCLC patients might be achieved.

\section{References}

1. Schiller JH, Harrington D, Belani CP Langer C Sandler A, et al. (2002) Comparison of four chemotherapy regimens for advanced non-small-cell lung cancer. N Engl J Med 346: 92-98.

2. Dunn GP, Old LJ, Schreiber RD (2004) The three Es of cancer immunoediting Annu Rev Immunol 22: 329-360.

3. Van Der Bruggen $\mathrm{P}$, Zhang $\mathrm{Y}$, Chaux $\mathrm{P}$, Stroobant $\mathrm{V}$, Panichelli $\mathrm{C}$, et al. (2002) Tumor-specific shared antigenic peptides recognized by human T cells. Immunol Rev 188: 51-64.

4. BURNET M (1957) Cancer: a biological approach. III. Viruses associated with neoplastic conditions. IV. Practical applications. Br Med J 1: 841-847.

5. Mellman I, Coukos G, Dranoff G (2011) Cancer immunotherapy comes of age. Nature 480: 480-489

6. Passlick B, Pantel K, Kubuschok B, Angstwurm M, Neher A, et al. (1996) Expression of MHC molecules and ICAM-1 on non-small cell lung carcinomas: association with early lymphatic spread of tumour cells. Eur $\mathrm{J}$ Cancer 32A: 141-145.

7. Kikuchi E, Yamazaki K, Torigoe T, Cho Y, Miyamoto M, et al. (2007) HLA class I antigen expression is associated with a favorable prognosis in early stage non-small cell lung cancer. Cancer Sci 98: 1424-1430.

8. Verdegaal EM, Hoogstraten C, Sandel MH, Kuppen PJ, Brink AA, et al. (2007) Functional CD8+ $T$ cells infiltrate into nonsmall cell lung carcinoma. Cancer Immunol Immunother 56: 587-600.

9. Al-Shibli KI, Donnem T, Al-Saad S, Persson M, Bremnes RM, et al. (2008) Prognostic effect of epithelial and stromal lymphocyte infiltration in non-small cell lung cancer. Clin Cancer Res 14: 5220-5227.

10. Van Pel A, van der Bruggen P, Coulie PG, Brichard VG, Lethé B, et al. (1995) Genes coding for tumor antigens recognized by cytolytic $T$ lymphocytes. Immunol Rev 145: 229-250.

11. Rosenberg SA (1997) Cancer vaccines based on the identification of genes encoding cancer regression antigens. Immunol Today 18: 175-182.

12. Van den Eynde BJ, van der Bruggen $P$ (1997) T cell defined tumor antigens. Curr Opin Immunol 9: 684-693.

13. Rosenberg SA (2001) Progress in human tumour immunology and immunotherapy. Nature 411: 380-384.
14. Gilboa E (2004) The promise of cancer vaccines. Nat Rev Cancer 4: 401-411.

15. Novellino L, Castelli C, Parmiani G (2005) A listing of human tumor antigens recognized by T cells: March 2004 update. Cancer Immunol Immunother 54 187-207.

16. Ichiki Y, Takenoyama M, Mizukami M, So T, Sugaya M, et al. (2004) Simultaneous cellular and humoral immune response against mutated p53 in a patient with lung cancer. J Immunol 172: 4844-4850.

17. Nagata $\mathrm{Y}$, Hanagiri T, Takenoyama M, Fukuyama T, Mizukami M, et al. (2005) Identification of the HLA-Cw*0702-restricted tumor-associated antigen recognized by a CTL clone from a lung cancer patient. Clin Cancer Res 11: 5265-5272.

18. So T, Takenoyama M, Mizukami M, Ichiki Y, Sugaya M, et al. (2005) Haplotype loss of HLA class I antigen as an escape mechanism from immune attack in lung cancer. Cancer Res 65: 5945-5952.

19. Takenoyama M, Baurain JF, Yasuda M, So T, Sugaya M, et al. (2006) A point mutation in the NFYC gene generates an antigenic peptide recognized by autologous cytolytic $T$ lymphocytes on a human squamous cell lung carcinoma. Int J Cancer 118: 1992-1997.

20. Fukuyama T, Hanagiri T, Takenoyama M, Ichiki Y, Mizukami M, et al. (2006) Identification of a new cancer/germline gene, KK-LC-1, encoding an antigen recognized by autologous CTL induced on human lung adenocarcinoma. Cancer Res 66: 4922-4928.

21. Sugaya M, Takenoyama M, Shigematsu Y, Baba T, Fukuyama T, et al. (2007) Identification of HLA-A24 restricted shared antigen recognized by autologous cytotoxic T lymphocytes from a patient with large cell carcinoma of the lung. Int J Cancer 120: 1055-1062.

22. van der Bruggen $P$, Traversari $C$, Chomez $P$, Lurquin $C$, De Plaen $E$, et al (1991) A gene encoding an antigen recognized by cytolytic T lymphocytes on a human melanoma. Science 254: 1643-1647.

23. Vansteenkiste J, Zielinski M, Linder A, Dahabreh J, Gonzalez EE, et al. (2013) Adjuvant MAGE-A3 immunotherapy in resected non-small-cell lung cancer: phase II randomized study results. J Clin Oncol 31: 2396-2403.

24. Harley CB, Kim NW, Prowse KR, Weinrich SL, Hirsch KS, et al. (1994) Telomerase, cell immortality, and cancer. Cold Spring Harb Symp Quant Biol 59: 307-315.

25. Kim NW, Piatyszek MA, Prowse KR, Harley CB, West MD, et al. (1994) Specific association of human telomerase activity with immortal cells and cancer. Science 266: 2011-2015

26. Shay JW (1997) Telomerase in human development and cancer. J Cell Physiol 173: $266-270$

27. Counter CM, Meyerson M, Eaton EN, Ellisen LW, Caddle SD, et al. (1998) Telomerase activity is restored in human cells by ectopic expression of hTERT (hEST2), the catalytic subunit of telomerase. Oncogene 16: 1217-1222.

28. Aloysius MM, Mc Kechnie AJ, Robins RA, Verma C, Eremin JM, et al. (2009) Generation in vivo of peptide-specific cytotoxic $T$ cells and presence of regulatory T cells during vaccination with hTERT (class I and II) peptide-pulsed DCs. J Transl Med 7: 18

29. Chen DY, Vance BA, Thompson LB, Domchek SM, Vonderheide RH (2007) Differential lysis of tumors by polyclonal $T$ cell lines and $T$ cell clones specific for hTERT. Cancer Biol Ther 6: 1991-1996.

30. Vonderheide RH, Domchek SM, Schultze JL, George DJ, Hoar KM, et al. (2004) Vaccination of cancer patients against telomerase induces functional antitumor CD8+ T lymphocytes. Clin Cancer Res 10: 828-839.

31. Wenandy L, Sørensen RB, Sengeløv L, Svane IM, thor Straten P, et al. (2008) The immunogenicity of the hTERT540-548 peptide in cancer. Clin Cancer Res 14: 4-7.

32. Bernhardt SL, Gjertsen MK, Trachsel S, Møller M, Eriksen JA, et al. (2006) Telomerase peptide vaccination of patients with non-resectable pancreatic cancer: A dose escalating phase I/II study. Br J Cancer 95: 1474-1482.

33. Brunsvig PF, Aamdal S, Gjertsen MK, Kvalheim G, Markowski-Grimsrud CJ, et al. (2006) Telomerase peptide vaccination: a phase I/II study in patients with non-small cell lung cancer. Cancer Immunol Immunother 55: 1553-1564.

34. Domchek SM, Recio A, Mick R, Clark CE, Carpenter EL, et al. (2007) Telomerase-specific T-cell immunity in breast cancer: effect of vaccination on tumor immunosurveillance. Cancer Res 67: 10546-10555. 
35. Su Z, Dannull J, Yang BK, Dahm P, Coleman D, et al. (2005) Telomerase mRNA-transfected dendritic cells stimulate antigen-specific CD8+ and CD4+ $\mathrm{T}$ cell responses in patients with metastatic prostate cancer. J Immunol 174 3798-3807.

36. Parkhurst MR, Riley JP, Igarashi T, Li Y, Robbins PF, et al. (2004) Immunization of patients with the hTERT:540-548 peptide induces peptidereactive T lymphocytes that do not recognize tumors endogenously expressing telomerase. Clin Cancer Res 10: 4688-4698.

37. Kyte JA, Gaudernack G, Dueland S, Trachsel S, Julsrud L, et al. (2011) Telomerase peptide vaccination combined with temozolomide: a clinical trial in stage IV melanoma patients. Clin Cancer Res 17: 4568-4580.

38. Hunger RE, Kernland Lang K, Markowski CJ, Trachsel S, Møller M, et al. (2011) Vaccination of patients with cutaneous melanoma with telomerasespecific peptides. Cancer Immunol Immunother 60: 1553-1564.

39. Kumaki F, Kawai T, Hiroi S, Shinomiya N, Ozeki Y, et al. (2001) Telomerase activity and expression of human telomerase RNA component and human telomerase reverse transcriptase in lung carcinomas. Hum Pathol 32: 188-195.

40. Fujita Y, Fujikane T, Fujiuchi S, Nishigaki Y, Yamazaki Y, et al. (2003) The diagnostic and prognostic relevance of human telomerase reverse transcriptase mRNA expression detected in situ in patients with nonsmall cell lung carcinoma. Cancer 98: 1008-1013.

41. Gahn B, Staudinger M, Woester K, Wellnitz D, Boettcher S, et al. (2013) In vitro activation of hTERT-specific $T$ cell responses in lung cancer patients following chemotherapy. J Thorac Dis 5: 240-250.

42. Brunsvig PF, Kyte JA, Kersten C, Sundstrøm S, Møller M, et al. (2011) Telomerase peptide vaccination in NSCLC: a phase II trial in stage III patients vaccinated after chemoradiotherapy and an 8-year update on a phase I/II trial. Clin Cancer Res 17: 6847-6857.

43. Theobald M, Biggs J, Hernández J, Lustgarten J, Labadie C, et al. (1997) Tolerance to p53 by A2.1-restricted cytotoxic T lymphocytes. J Exp Med 185: 833-841.

44. Colella TA, Bullock TN, Russell LB, Mullins DW, Overwijk WW, et al. (2000) Self-tolerance to the murine homologue of a tyrosinase-derived melanoma antigen: implications for tumor immunotherapy. J Exp Med 191: 1221-1232.

45. Gross DA, Graff-Dubois S, Opolon P, Cornet S, Alves P, et al. (2004) High vaccination efficiency of low-affinity epitopes in antitumor immunotherapy. J Clin Invest 113: 425-433

46. Cibotti R, Kanellopoulos JM, Cabaniols JP, Halle-Panenko O, Kosmatopoulos $\mathrm{K}$, et al. (1992) Tolerance to a self-protein involves its immunodominant but does not involve its subdominant determinants. Proc Natl Acad Sci U S A 89: 416-420.

47. Grossmann ME, Davila E, Celis E (2001) Avoiding tolerance against prostatic antigens with subdominant peptide epitopes. J Immunother 24: 237-241.

48. Scardino A, Gross DA, Alves P, Schultze JL, Graff-Dubois S, et al. (2002) HER$2 /$ neu and hTERT cryptic epitopes as novel targets for broad spectrum tumor immunotherapy. J Immunol 168: 5900-5906.

49. Hernandez J, Garcia-Pons F, Lone YC, Firat H, Schmidt JD, et al. (2002) Identification of a human telomerase reverse transcriptase peptide of low affinity for HLA A2.1 that induces cytotoxic T lymphocytes and mediates lysis of tumor cells. Proc Natl Acad Sci U S A 99: 12275-12280.

50. Bolonaki I, Kotsakis A, Papadimitraki E, Aggouraki D, Konsolakis G, et al (2007) Vaccination of patients with advanced non-small-cell lung cancer with an optimized cryptic human telomerase reverse transcriptase peptide. J Clin Oncol 25: 2727-2734.

51. Gendler SJ, Lancaster CA, Taylor-Papadimitriou J, Duhig T, Peat N, et al. (1990) Molecular cloning and expression of human tumor-associated polymorphic epithelial mucin. J Biol Chem 265: 15286-15293.

52. Müller S, Alving K, Peter-Katalinic J, Zachara N, Gooley AA, et al. (1999) High density O-glycosylation on tandem repeat peptide from secretory MUC1 of T47D breast cancer cells. J Biol Chem 274: 18165-18172.

53. Barnd DL, Lan MS, Metzgar RS, Finn OJ (1989) Specific, major histocompatibility complex-unrestricted recognition of tumor-associated mucins by human cytotoxic T cells. Proceedings of the Proc Natl Acad Sci U S A 86: 7159-7163.

54. Doménech N, Henderson RA, Finn OJ (1995) Identification of an HLA-A11restricted epitope from the tandem repeat domain of the epithelial tumor antigen mucin. J Immunol 155: 4766-4774.

55. Apostolopoulos V, Karanikas V, Haurum JS, McKenzie IF (1997) Induction of HLA-A2-restricted CTLs to the mucin 1 human breast cancer antigen. $J$ Immunol 159: 5211-5218.
56. Brossart P, Heinrich KS, Stuhler G, Behnke L, Reichardt VL, et al. (1999) Identification of HLA-A2-restricted T-cell epitopes derived from the MUC1 tumor antigen for broadly applicable vaccine therapies. Blood 93: 4309-4317.

57. Hiltbold EM, Ciborowski P, Finn OJ (1998) Naturally processed class II epitope from the tumor antigen MUC1 primes human CD4+ T cells. Cancer Res 58: 5066-5070.

58. Sharma S, Srivastava MK, Harris-White M, Lee JM, Dubinett S (2011) MUC1 peptide vaccine mediated antitumor activity in non-small cell lung cancer Expert Opin Biol Ther 11: 987-990.

59. Sangha R, North S (2007) L-BLP25: a MUC1-targeted peptide vaccine therapy in prostate cancer. Expert Opin Biol Ther 7: 1723-1730.

60. Ohyanagi F, Horai T, Sekine I, Yamamoto N, Nakagawa K, et al. (2011) Safety of BLP25 liposome vaccine (L-BLP25) in Japanese patients with unresectable stage III NSCLC after primary chemoradiotherapy: preliminary results from a Phase I/II study. Jpn J Clin Oncol 41: 718-722.

61. Palmer M, Parker J, Modi S, Butts C, Smylie M, et al. (2001) Phase I study of the BLP25 (MUC1 peptide) liposomal vaccine for active specific immunotherapy in stage IIIB/IV non-small-cell lung cancer. Clin Lung Cancer 3: 49-57.

62. Butts C, Maksymiuk A, Goss G, Soulières D, Marshall E, et al. (2011) Updated survival analysis in patients with stage IIIB or IV non-small-cell lung cancer receiving BLP25 liposome vaccine (L-BLP25): phase IIB randomized, multicenter, open-label trial. J Cancer Res Clin Oncol 137: 1337-1342.

63. Ramlau R, Quoix E, Rolski J, Pless M, Lena H, et al. (2008) A phase II study of Tg4010 (Mva-Muc1-II2) in association with chemotherapy in patients with stage III/IV Non-small cell lung cancer. J Thorac Oncol 3: 735-744.

64. Dreicer R, Stadler WM, Ahmann FR, Whiteside T, Bizouarne N, et al. (2009) MVA-MUC1-IL2 vaccine immunotherapy (TG4010) improves PSA doubling time in patients with prostate cancer with biochemical failure. Invest New Drugs 27: 379-386.

65. Oudard S, Rixe O, Beuselinck B, Linassier C, Banu E, et al. (2011) A phase II study of the cancer vaccine TG4010 alone and in combination with cytokines in patients with metastatic renal clear-cell carcinoma: clinical and immunological findings. Cancer Immunol Immunother 60: 261-271.

66. Quoix E, Ramlau R, Westeel V, Papai Z, Madroszyk A, et al. (2011) Therapeutic vaccination with TG4010 and first-line chemotherapy in advanced non-smallcell lung cancer: a controlled phase 2B trial. Lancet Oncol 12: 1125-1133.

67. Ulloa-Montoya F, Louahed J, Dizier B, Gruselle O, Spiessens B, et al. (2013) Predictive gene signature in MAGE-A3 antigen-specific cancer immunotherapy J Clin Oncol 31: 2388-2395.

68. Freeman GJ, Long AJ, Iwai Y, Bourque K, Chernova T, et al. (2000) Engagemen of the PD-1 immunoinhibitory receptor by a novel B7 family member leads to negative regulation of lymphocyte activation. J Exp Med 192: 1027-1034.

69. Iwai Y, Ishida M, Tanaka Y, Okazaki T, Honjo T, et al. (2002) Involvement of PD-L1 on tumor cells in the escape from host immune system and tumo immunotherapy by PD-L1 blockade. Proc Natl Acad Sci U S A 99: 1229312297.

70. Topalian SL, Hodi FS, Brahmer JR, Gettinger SN, Smith DC, et al. (2012) Safety, activity, and immune correlates of anti-PD-1 antibody in cancer. N Eng J Med 366: 2443-2454

71. Sporn MB, Roberts AB, Wakefield LM, Assoian RK (1986) Transforming growth factor-beta: biological function and chemical structure. Science 233: 532-534.

72. Bodmer S, Strommer K, Frei K, Siepl C, de Tribolet N, et al. (1989) Immunosuppression and transforming growth factor-beta in glioblastoma. Preferential production of transforming growth factor-beta 2 . J Immunol 143 3222-3229.

73. Jakowlew SB, Mathias A, Chung P, Moody TW (1995) Expression of transforming growth factor beta ligand and receptor messenger RNAs in lung cancer cell lines. Cell Growth Differ 6: 465-476.

74. Kong F, Jirtle RL, Huang DH, Clough RW, Anscher MS (1999) Plasma transforming growth factor-beta1 level before radiotherapy correlates with long term outcome of patients with lung carcinoma. Cancer 86: 1712-1719.

75. Marzo AL, Fitzpatrick DR, Robinson BW, Scott B (1997) Antisense oligonucleotides specific for transforming growth factor beta2 inhibit the growth of malignant mesothelioma both In vitro and in vivo. Cancer Res 57: 3200-3207.

76. Nemunaitis J, Dillman RO, Schwarzenberger PO, Senzer N, Cunningham C, et al. (2006) Phase II study of belagenpumatucel-L, a transforming growth factor beta-2 antisense gene-modified allogeneic tumor cell vaccine in non-small-cell lung cancer. J Clin Oncol 24: 4721-4730. 